\title{
Dor procedure for dyskinetic anteroapical myocardial infarction fails to improve contractility in the border zone
}

\author{
Kay Sun, PhD, ${ }^{\mathrm{a}, \mathrm{e}}$ Zhihong Zhang, MS, ${ }^{\mathrm{a}, \mathrm{e}}$ Takamaro Suzuki, MD, ${ }^{\mathrm{a}, \mathrm{e}}$ Jonathan F. Wenk, PhD, \\ Nielen Stander, PhD, ${ }^{\mathrm{f}}$ Daniel R. Einstein, $\mathrm{PhD},{ }^{\mathrm{g}}$ David A. Saloner, $\mathrm{PhD},{ }^{\mathrm{d}, \mathrm{e}}$ Arthur W. Wallace, MD, PhD, ${ }^{\mathrm{c}, \mathrm{e}}$ \\ Julius M. Guccione, $\mathrm{PhD},{ }^{\mathrm{a}, \mathrm{b}, \mathrm{e}}$ and Mark B. Ratcliffe, $\mathrm{MD}^{\mathrm{a}, \mathrm{b}, \mathrm{e}}$
}

Background: Endoventricular patch plasty (Dor) is used to reduce left ventricular volume after myocardial infarction and subsequent left ventricular remodeling.

\begin{abstract}
Methods and Results: End-diastolic and end-systolic pressure-volume and Starling relationships were measured, and magnetic resonance images with noninvasive tags were used to calculate 3-dimensional myocardial strain in 6 sheep 2 weeks before and 2 and 6 weeks after the Dor procedure. These experimental results were previously reported.

The imaging data from 1 sheep were incomplete. Animal specific finite element models were created from the remaining 5 animals using magnetic resonance images and left ventricular pressure obtained at early diastolic filling. Finite element models were optimized with 3-dimensional strain and used to determine systolic material properties, $\mathrm{T}_{\text {max,skinned-fiber, }}$, and diastolic and systolic stress in remote myocardium and border zone.
\end{abstract}

Six weeks after the Dor procedure, end-diastolic and end-systolic stress in the border zone were substantially reduced. However, although there was a slight increase in $\mathrm{T}_{\text {max,skinned-fiber }}$ in the border zone near the myocardial infarction at 6 weeks, the change was not significant.

Conclusions: The Dor procedure decreases end-diastolic and end-systolic stress but fails to improve contractility in the infarct border zone. Future work should focus on measures that will enhance border zone function alone or in combination with surgical remodeling. (J Thorac Cardiovasc Surg 2010;140:233-9)

\section{Supplemental material is available online.}

Initially described by Dor and associates ${ }^{1}$ in 1989 , endoventricular patch plasty (Dor procedure) is used to reduce left ventricular (LV) volume after myocardial infarction (MI) and subsequent LV remodeling. In brief, the infarct is incised and a pursestring suture (Fontan stitch) used to reduce the circumference of the aneurysm "neck." A patch of either autologous or synthetic material is then sewn to the edge of the aneurysm neck, thereby reducing LV volume. ${ }^{1}$

\footnotetext{
From the Departments of Surgery, ${ }^{\mathrm{a}}$ Bioengineering, ${ }^{\mathrm{b}}$ Anesthesia, ${ }^{\mathrm{c}}$ and Radiology, ${ }^{\mathrm{d}}$ University of California, San Francisco, Calif; Veterans Affairs Medical Center, ${ }^{\text {e }}$ San Francisco, Calif; Livermore Software Technology Corporation, ${ }^{\mathrm{f}}$ Livermore, Calif; and Biological Monitoring and Modeling, ${ }^{\mathrm{g}}$ Pacific Northwest National Laboratory, Olympia, Wash.

This study was supported by National Institutes of Health grant R01-HL-77921 (to Dr Guccione), VA Merit Review (to Dr Wallace), and R01-HL-63348 (to Dr Ratcliffe). Disclosures: None.

Received for publication June 7, 2009; revisions received Nov 13, 2009; accepted for publication Nov 23, 2009; available ahead of print March 18, 2010.

Address for reprints: Mark Ratcliffe, MD, Surgical Service (112), San Francisco Veterans Affairs Medical Center, 4150 Clement St, San Francisco, CA 94121 (E-mail: mark.ratcliffe@med.va.gov).

0022-5223/\$0.00

Published by Elsevier Inc. on behalf of The American Association for Thoracic Surgery

doi:10.1016/j.jtcvs.2009.11.055
}

The Dor procedure can be performed safely., ${ }^{2,3}$ However, the Surgical Treatment for Ischemic Heart failure (STICH) trial, sponsored by the National Institutes of Health, recently found no difference in composite outcome between coronary artery bypass grafting (CABG) and CABG plus Dor procedure. ${ }^{4}$ The authors speculated that improved systolic function was balanced by worsened diastolic function. ${ }^{4}$ On the other hand, even if pump function is not improved, the Dor procedure may have important effects on stress, strain, and contractility in the infarct border zone (BZ).

It has been known since the mid-1980s that systolic function (systolic shortening and wall thickening) is depressed in the nonischemic infarct BZ. ${ }^{5}$ It was initially thought that reduced $\mathrm{BZ}$ shortening was due to mechanical tethering (high systolic stress) by the infarct. To better clarify the cause, we previously created a finite element model of the LV that was based on magnetic resonance imaging (MRI) data obtained after anteroapical MI in sheep. ${ }^{6,7}$ Model output was optimized by comparing strain predicted by the model with strain measured using MRI. Surprisingly, the finite element (FE) simulations showed that BZ contractility was significantly depressed. Specifically, BZ contractility was found to be $50 \%$ of that in the remote uninfarcted myocardium. ${ }^{6}$

It has been suggested that the Dor procedure reduces BZ stress and strain and as a consequence BZ contractility would improve. ${ }^{8}$ The primary goal of the present study was, therefore, to quantify the effect of the Dor procedure 


$$
\begin{aligned}
& \text { Abbreviations and Acronyms } \\
& \begin{aligned}
\mathrm{BZ}= & \text { border zone } \\
\mathrm{CABG}= & \text { coronary artery bypass grafting } \\
\mathrm{LV}= & \text { left ventricular } \\
\mathrm{MI}= & \text { myocardial infarction } \\
\mathrm{MRI}= & \text { magnetic resonance imaging (image) } \\
\mathrm{MSE}= & \text { mean square error } \\
\mathrm{STICH}= & \text { Surgical Treatment for Ischemic } \\
& \text { Heart failure } \\
T_{\max }= & \text { maximum isometric tension achieved } \\
& \text { at the longest sacromere length }
\end{aligned}
\end{aligned}
$$

on BZ contractility and stress using MRI-based FE models. We tested the hypothesis that the Dor procedure will decrease diastolic and systolic stress and increase regional myocardial contractility in the infarct BZ in sheep.

\section{MATERIAL AND METHODS \\ Experimental Measurements}

End-diastolic and end-systolic pressure-volume and Starling relationships were measured ${ }^{9}$ and MRIs with noninvasive tags used to calculate 3 -dimensional myocardial strain ${ }^{10}$ in 6 sheep 2 weeks before and then 2 and 6 weeks after the Dor procedure. These experimental results were previously reported.

Specifically, an elliptical Dacron patch was fashioned so that the major and minor axes were $50 \%$ of the corresponding infarct neck on the MRI. An incision was made in the apical infarct, and the transition between infarcted aneurysm and uninfarcted myocardium was determined by inspection and palpation. The patch was positioned parallel to the septum and sutured to the line of transition with interrupted 2-0 Ethibond Excel suture (Ethicon, Inc, Somerville, NJ). All dyskinetic portions of the anterior wall and septum were excluded. ${ }^{9}$

Previously reported end-diastolic and end-systolic pressures and volumes are seen in Table E1. ${ }^{9}$ Representative long-axis MRIs before and after the Dor procedure are seen in Figure E1. ${ }^{10}$

FE model. The imaging data from 1 sheep were incomplete. Animal specific FE models were created from the remaining 5 animals using MRIs and LV pressure obtained at early diastolic filling. A flow chart of overall FE/material property optimization method is seen in Figure E2.

The BZ infarct intersection was defined manually. The remote BZ intersection was defined as the point where the wall thickness is $70 \%$ of the maximum wall thickness and the intersection between intermediate BZ (BZ1) and BZ near MI (BZ2) was midway between the BZ infarct and remote $\mathrm{BZ}$ intersections.

From the LV contours, surface meshes were created to replicate the in vivo geometry (Rapidform; INUS Technology, Inc, Sunnyvale, Calif). The spaces between the endocardium and epicardium surfaces were filled with 8-noded brick elements, each with a single integration point, to generate a volumetric mesh that is 3 elements thick transmurally and has a different material for each of the 4 regions (Truegrid; XYZ Scientific Applications, Inc., Livermore, Calif). Representative surface and FE meshes are seen in Figure 1.

Cardiac myofiber angles of $-37^{\circ}, 23^{\circ}$, and $83^{\circ}$ were assigned at the epicardium, midwall, and endocardium, respectively, in the remote and BZ regions. ${ }^{11}$ At the aneurysm region, fiber angles were set to $0^{\circ}$ to use experimentally determined aneurysm material parameters with respect to this direction. ${ }^{12}$ Nodes at the LV base were only allowed to move in the plane of the LV base and basal epicardial nodes were fixed. The LV endocardial surface was loaded to the measured in vivo end-diastolic and endsystolic LV pressures.

Material parameters. Passive ${ }^{13}$ and active myocardial ${ }^{14}$ material property laws (see Appendix) were implemented using a user-defined material subroutine in the explicit FE solver, LS-DYNA (Livermore Software Technology Corporation, Livermore, Calif).

Diastolic materials parameters, $b_{\mathrm{f}}, b_{\mathrm{t}}$, and $b_{\mathrm{fs}}$, were set to the average optimized values for sheep obtained previously from Walker and associates ${ }^{7}$ : $b_{\mathrm{f}}=49.25, b_{\mathrm{t}}=19.25, b_{\mathrm{fs}}=17.44$. $C$ in the remote myocardium was determined so that the calculated end-diastolic LV volume matched the measured value. For the pre-Dor models, $C$ in the aneurysm region was defined as 10 times stiffer than that in the remote. ${ }^{15}$ The patch was assumed to be isotropic and made of a very stiff material, with Young's modulus $=10$ $\mathrm{GPa}$ and Poisson's ratio $=0.3$.

The material constants for active contraction were found to be as follows ${ }^{16}: C a_{0}=4.35 \mu \mathrm{mol} / \mathrm{L},\left(C a_{0}\right)_{\max }=4.35 \mu \mathrm{mol} / \mathrm{L}, B=4.75 \mu \mathrm{m}^{-1}, l_{O}$ $=1.58 \mu \mathrm{m}, m=1.0489 \mathrm{~s} \mu \mathrm{m}^{-1}, b=-1.429 \mathrm{~s}$, and $l_{\mathrm{R}}$ was set at $1.85 \mu \mathrm{m}$, the sacromere length in the unloaded configuration. On the basis of the biaxial stretching experiments ${ }^{17}$ and FE analyses, ${ }^{7,18}$ cross-fiber, in-plane stress equivalent to $40 \%$ of that along the myocardial fiber direction was added.

Material parameter optimization. The commercial FE optimization software, LS-OPT (Livermore Software Technology Corporation), was used to find the optimum systolic material properties in the remote myocardium and the BZ. ${ }^{19} \mathrm{FE}$ simulations were performed and the mean square errors (MSE) for all points were calculated. The MSE is defined as the difference between the computed FE and experimental results (end-diastolic and end-systolic volumes and strains).

$$
M S E=\sum_{n=1}^{N} \sum_{i=1,2,3 ; j=1,2,3 ; i \neq 3 j \neq 3}\left(E_{i j, n}-\bar{E}_{i j, n}\right)^{2}+\left(\frac{V_{\mathrm{ED}}-\bar{V}_{\mathrm{ED}}}{\bar{V}_{\mathrm{ED}}}\right)^{2}+\left(\frac{V_{\mathrm{SD}}-\bar{V}_{\mathrm{SD}}}{\bar{V}_{\mathrm{SD}}}\right)^{2}
$$

where $n$ is the in vivo strain point, $N$ is the total number of in vivo strain points, $E_{i j, S}$ is the computed $\mathrm{FE}$ strain at each strain point, and $V_{\mathrm{ED}}$ and $V_{\mathrm{SD}}$ are the computed FE end-diastolic and end-systolic LV volumes, respectively. The overbar represents experimental in vivo measurements. Strain in the radial direction, $E_{33}$, is excluded inasmuch as it cannot be measured with sufficient accuracy with tagged MRIs. ${ }^{20,21}$ The goal of the optimization is to minimize the MSE.

Since tagged MRIs were acquired during systole, only systolic myocardial strains could be determined. This meant that only systolic material parameters, $T_{\text {max_twitch }}$ in remote $\left(T_{\text {max_twitch_R }}\right)$ and $\mathrm{BZ}$ regions ( $T_{\text {max_twitch_intermediate }}$ and $T_{\text {max_twitch_nearMI }}$ ), could be optimized. $T_{\text {max_twitch }}$ in the aneurysm region was set to zero as the coronary ligations were permanently put in place to create dyskinetic infarcts. Initial ranges for $T_{\max \_\mathrm{R}}$ were between 0.1 and $1000.0 \mathrm{kPa}$, and between 0.1 and $500.0 \mathrm{kPa}$ for $T_{\text {max_B }}$.

\section{Statistical analysis}

All values are expressed as mean \pm standard deviation and compared by repeated measures analysis using a mixed model to test for both fixed and random effects. We performed the analysis using SAS PROC MIXED (SAS system for Windows version 9.1; SAS Institute, Inc, Cary, NC), which uses a maximum likelihood or restricted maximum likelihood estimation technique as opposed to ordinary least squares. As a consequence, subjects with missing data were not automatically deleted from the analysis. Also, variables can be either continuous or categorical and relationships between the variables can be linear or curvilinear inasmuch as the mixed model does not assume a normal distribution. ${ }^{22}$ The statistical model was as follows:

$T_{\text {max_twitch,Difference }}=$ Time + Zone $+T_{\text {max_twitch,preoperative }}$

where Difference $=$ difference between preoperative and postoperative values and Zone is the different regions (remote and 2 separate $\mathrm{BZ}$ regions). 

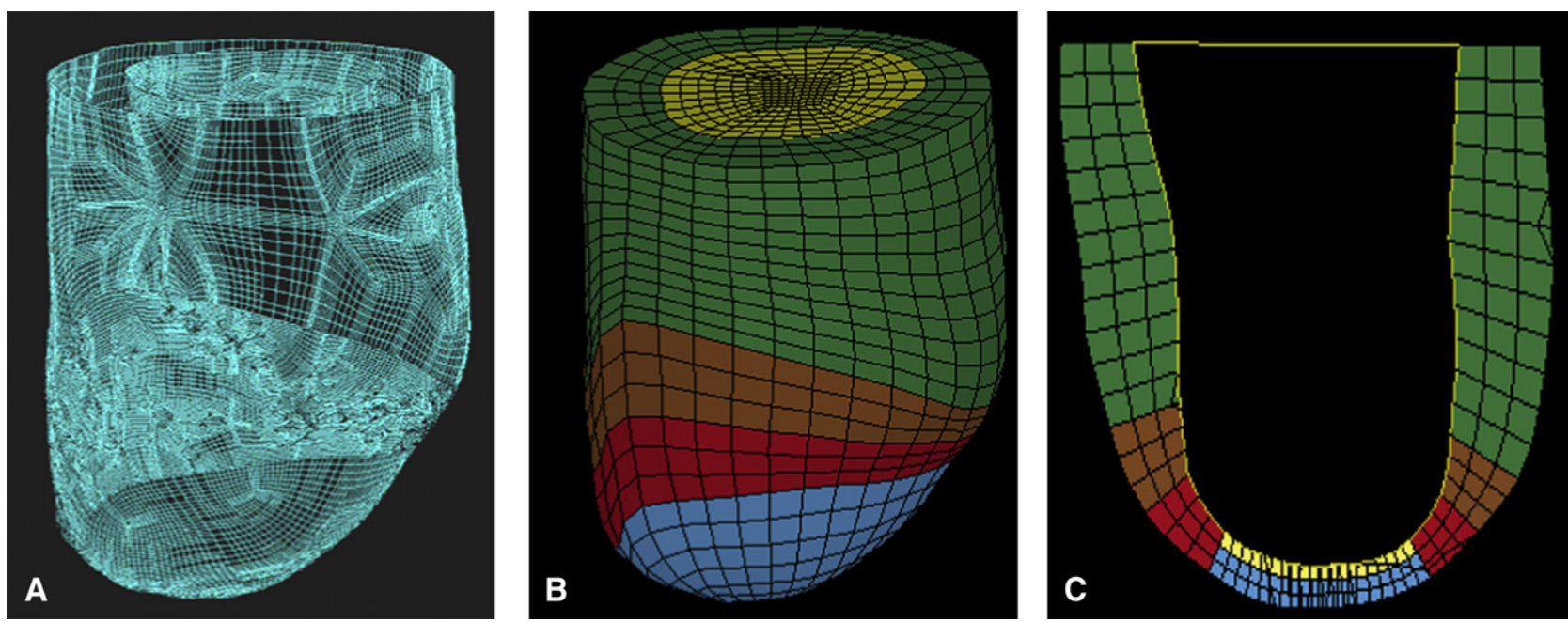

FIGURE 1. Finite element model of the left ventricle with anteroapical myocardial infarction. Animal specific contours were generated from magnetic resonance images (A). Solid mesh (B) was broken into 4 regions ( green = remote, brown = border zone 1 [intermediate], red $=$ border zone 2 [near myocardial infarction], blue = myocardial infarction) defined by wall thickness. Long-axis cross-section (C) at end-systole 6 weeks after the Dor procedure in a typical sheep (yellow $=$ patch).

As can be seen, the difference between pretreatment and posttreatment strain was used as the dependent variable and absolute pretreatment strain was used as a covariate. ${ }^{23}$ A similar statistical model was used to determine changes in fiber stress. The statistical significance of individual group comparisons was tested using the Student $t$ test. Owing to the large number of between zone comparisons, no multiple-comparison corrections were applied.

\section{RESULTS}

All 5 infarcted sheep survived the Dor procedure and completed the entire protocol. Weight loss was minimal. Previously reported LV pressure and volume from these same animals are shown in Table E1. ${ }^{9,10}$ Two weeks postoperatively, the Dor procedure had a significant effect on enddiastolic pressure $(P<.0475)$ and volume $(P<.0027)$ and end-systolic volume $(P<.0260)$. Six weeks postoperatively, the Dor procedure had a significant effect on end-diastolic $(P<.0119)$ and end-systolic volume $(P<.0072)$ and ejection fraction $(P<.0058)$. There was no trend toward redilation: Specifically, no significant difference was observed in end-diastolic volume $(P=.560)$ or end-systolic volume $(P=.801)$ between 2 and 6 weeks after the Dor procedure. ${ }^{9,10}$

The reliability of the predictions from the 5 models was tested with a mesh convergence study to find the minimum number of elements needed to produce accurate results within the fastest computation time. The mesh convergence study determined that 2496 elements are required and further mesh refinement only results in a $1 \%$ change in strain prediction.

Figure E3 shows how MSE (normalized to MSE at iteration $=0$ ) changes during the optimization. Table E2 documents the close agreement between measured and predicted circumferential strains and LV volume.

Figure 2 shows the effect of the Dor procedure on the optimum systolic material property. Panel A includes $T_{\text {max }}$,twitch generated by the optimization routine. In panel $\mathrm{B}$, values have been corrected so that they correspond to results of skinned fiber preparation ( $T_{\text {max,skinned-fiber }}$; equation 5 ). Note the decrease in $T_{\text {max,skinned-fiber }}$ in the remote myocardium, intermediate BZ, and BZ near the MI (24.4\%, $73.9 \%$, and $78.5 \%$, respectively) 2 weeks after the Dor procedure. There was a slight increase in $T_{\text {max skinned-fiber }}$ in the BZ near the MI at 6 weeks but the change was not significant.

Figure E4 shows the effect of the Dor procedure on stress at end-diastole (A) and end-systole (B). Pre-Dor and 2 week post-Dor midwall fiber stress at end-diastole were similar. Note the decrease in midwall fiber stress at end-diastole in the intermediate $\mathrm{BZ}$ and $\mathrm{BZ}$ near the $\mathrm{MI}(56.0 \%$ and $60.1 \%$, respectively) between 2 and 6 weeks after Dor. Pre-Dor and 2-week post-Dor fiber stress distributions at end-systole are shown in long-axis cross-sections (Figure 3).

There was an overall reduction in midwall fiber stress at end-systole, but only the decrease in midwall fiber stress at end-systole in the BZ near the MI (28.5\%) between 2 and 6 weeks after the Dor procedure was significant.

\section{DISCUSSION}

The primary finding of this study is that the Dor procedure decreases end-diastolic and end-systolic stress but fails to improve contractility in the infarct BZ.

\section{The STICH Trial}

The STICH trial, sponsored by the National Institutes of Health, recently found no difference in composite outcome between CABG and CABG plus the Dor procedure. ${ }^{4}$ This corroborates previous mathematical simulations ${ }^{24,25}$ and animal studies 9 of the Dor procedure in which the LV pump function failed to improve. In each case, a shift to the left of the end-systolic pressure-volume relationship was balanced or 

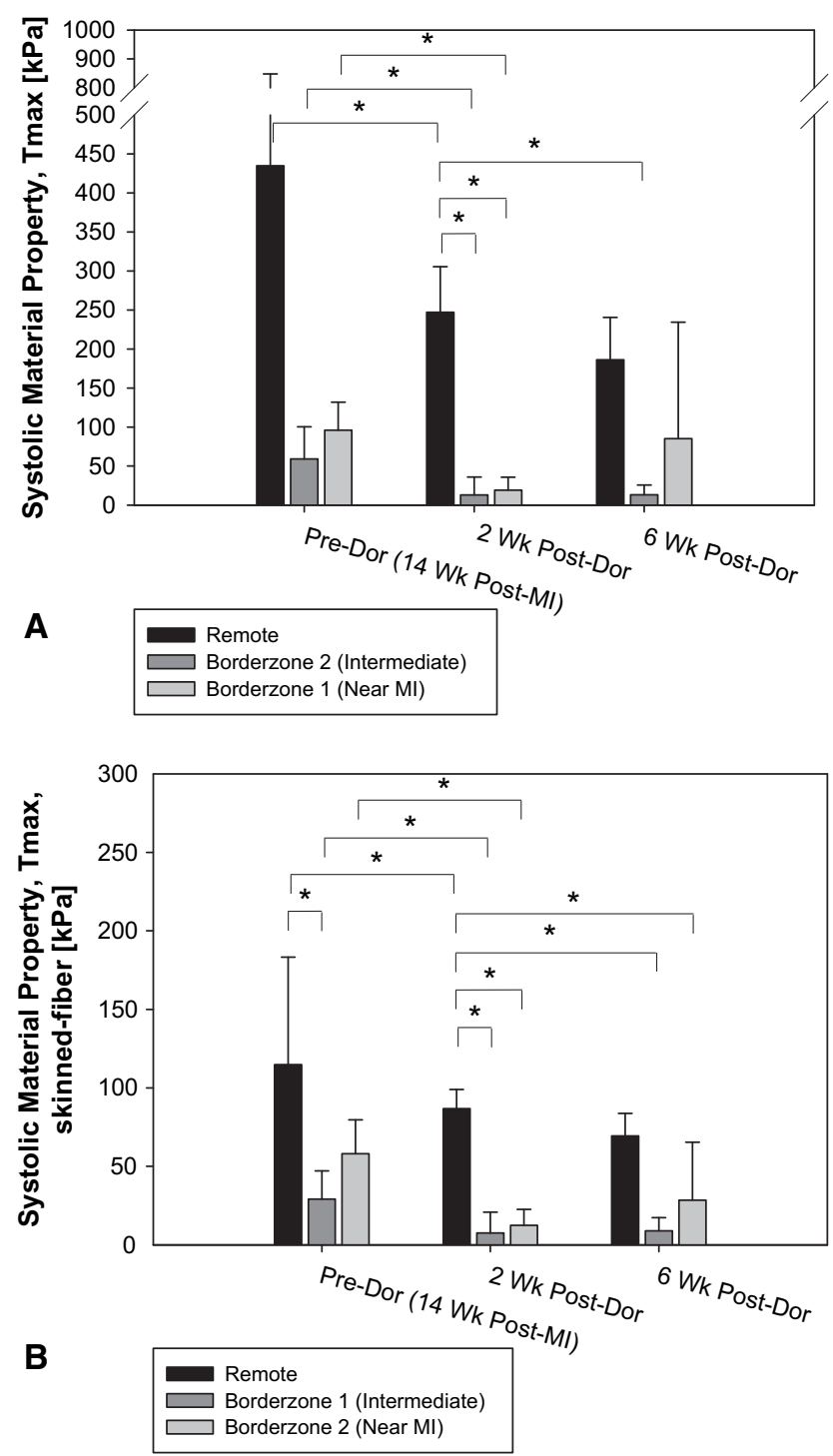

FIGURE 2. Calculated systolic material property, $T_{\max }$, after the Dor procedure. A, $T_{\text {max,twitch }}$ generated by the optimization routine. B, Values have been corrected so that they correspond to results of a skinned fiber preparation ( $T_{\text {max }, \text { skinned-fiber }}$; equation 5). Note the decrease in $\mathrm{T}_{\max }$ in the infarct border zone. Also, there is an increase in border zone $\mathrm{T}_{\max }$ at 6 weeks, but the change was not significant. Data are presented as mean + standard deviation. $* P<.05 . M I$, Myocardial infarction.

exceeded by a shift of the end-diastolic pressure-volume relationship. The resultant effect on pump function was neutral. ${ }^{9}$ However, even if the effect of the Dor procedure on pump function is neutral, the Dor procedure might reduce BZ stress and strain and as a consequence improve regional BZ contractility. ${ }^{8}$

\section{Calculation of Myocardial Material Properties With the Inverse FE Method}

Moulton and colleagues ${ }^{26}$ were the first to show that material properties of passive, diastolic myocardium could be determined by the FE method. Moulton's group ${ }^{26}$ deter- mined material parameters by minimizing the least squares difference between FE model-predicted and MRI-measured diastolic strain.

The gradient-free response surface optimization method $^{27}$ used in this study achieved good agreement between calculated and measured strain and has significant advantages. Response surface optimization has inherent noise-filtering properties ${ }^{28}$ and should become popular for biomechanical design applications where the response can be highly nonlinear.

\section{Interpretation of $\mathbf{T}_{\max }$}

In our mathematical model for active stress development in ventricular muscle, ${ }^{14,29} T_{\max }$ is the isometric tension achieved at the longest sarcomere length and maximum peak intracellular calcium concentration. An alternative approach to changing BZcontractility using our mathematical model is to vary peak intracellular calcium concentration. However, this also would change the shape of the active stress-sarcomere length relationship. ${ }^{14}$ For simplicity, we only allowed the regional values of $T_{\max }$ (and not peak intracellular calcium concentration) to be optimized to best fit myocardial strain measurements.

Kentish and associates ${ }^{30}$ have shown that maximal force developed by skinned rat ventricular trabeculae at saturation levels of calcium concentration depends on sarcomere length. To remove this load dependence, we define our index of contractility, $T_{\max }$, to be the maximal stress developed at the highest calcium concentration and the longest sarcomere length. Our stress-strain equations for systolic ventricular myocardium can accurately simulate the data measured by Kentish and associates ${ }^{30}$ from rat ventricular trabeculae before the muscles were skinned with the detergent Triton X-100.

\section{Contractility in the $\mathrm{BZ}$}

As above, BZ contractility is depressed after anteroapical MI. The cause is unclear but is probably initiated by high stress and strain in the BZ myocardium. High systolic stress and positive strain in the BZ initiates myocyte apoptosis ${ }^{31,32}$ and activation of matrix metalloproteinases 2 and 9. ${ }^{33,34}$ Activated matrix metalloproteinase 2 has been shown to directly damage the intracellular contractile proteins myocin light chain 1 and troponin I. ${ }^{35,36}$

The LV wall is thin in the BZ near to the infarct (BZ2). This is best seen in Figure E1. Wall thickness is a predictor of functional recovery in hibernating myocardium, ${ }^{37,38}$ and that hibernating myocardium with an end-diastolic wall thickness less than $0.6 \mathrm{~cm}$ in humans is unlikely to recover. ${ }^{38}$ However, the myocardium in peri-infarct BZ in sheep has a normal blood supply. ${ }^{8}$ Furthermore, contractile reserve in hibernating myocardium is inversely correlated with interstitial fibrosis ${ }^{39}$ and, with the exception of a rim of BZ immediately adjacent to the infarct, the infarct BZ in sheep does not have increased interstitial fibrosis. For these reasons, 


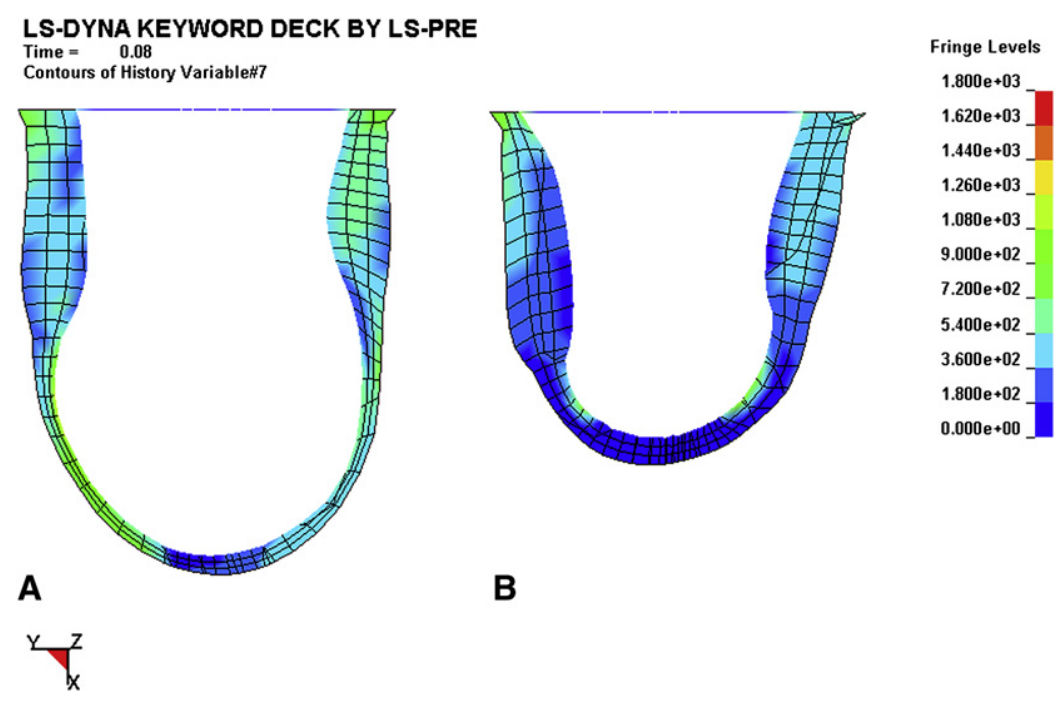

FIGURE 3. Effect of Dor procedure on longitudinal and transmural distributions of end-systolic myofiber stress pre-Dor (left) and 6 weeks post-Dor (right) in a typical sheep (corresponds to Figure 3, C). Fringe levels are in units of $\mathrm{hPa}=0.1 \mathrm{kPa}=0.1 \mathrm{mN} / \mathrm{mm}^{2}$. Note that stress concentrations (green surrounded by blue in the subendocardium of the infarct border zone pre-Dor still remain 6 weeks post-Dor. Additionally, wall thickening in the remote region 6 weeks postDor is much greater than that pre-Dor. Finally, note that the end-systolic myocardial material properties are different between these 2 states separated by 6 weeks.

we believe that it is very reasonable to continue to look for medical and surgical therapies that increase BZ function.

Despite stress reduction, our FE-based calculations show that BZ contractility is not improved after the Dor procedure. We thought that 6 weeks after the Dor procedure would be sufficient for BZ recovery. However, long-term observation after the Dor procedure in this animal model may be necessary.

We tested the hypothesis that enhanced BZ contractility after the Dor procedure would improve LV function. Specifically, the sheep $50 \mathrm{FE}$ model was rerun with $T_{\max , B Z}=$ $T_{\max , \text { Remote }}$. Sheep 50 is illustrious because it was the animal with the lowest cardiac output after the Dor procedure. Figure 4 shows the effect of enhanced BZ contractility on endsystolic elastance and the Starling law in sheep 50. Note the significant increase in stroke volume at the given LV pressure at end-diastole.

\section{Contractility in the Remote Myocardium}

In our first FE modeling study of BZ contractility, ${ }^{6}$ we did not allow $T_{\max }$ in the remote region to vary. Instead, we set $T_{\max }=81.4 \mathrm{kPa}$ in the remote region at the end of isovolumic contraction and varied $T_{\max }$ in the $\mathrm{BZ}$ region until our
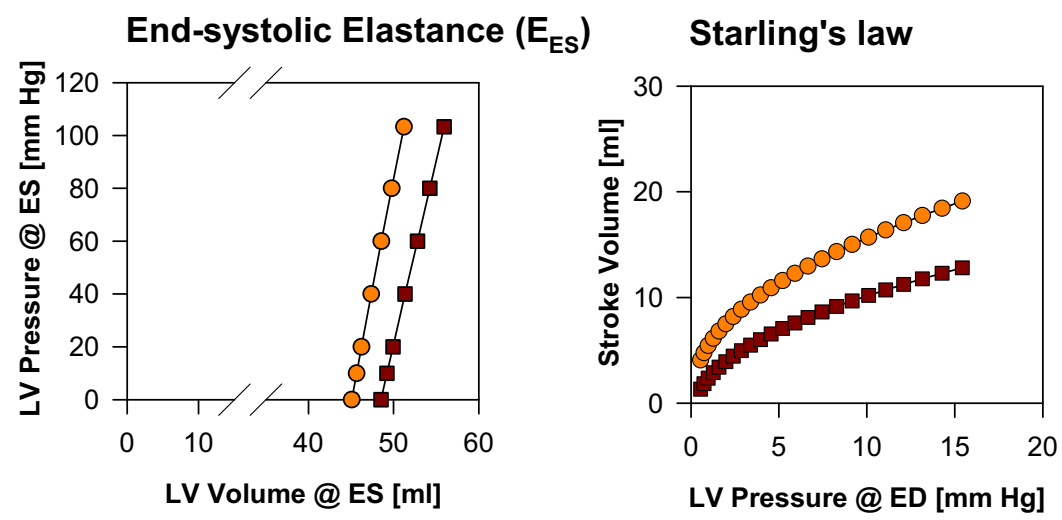

$\rightarrow$ Dor with depressed BZ Tmax

- - Dor with normal BZ Tmax

FIGURE 4. Effect of enhanced border zone $(B Z)$ contractility after the Dor procedure in sheep 50 on end-systolic elastance $\left(E_{E S}\right)$ and the Starling law. Results were obtained by re-running the finite element analysis with $T_{\max }$, twitch in the BZ equal to that in the remote. $L V$, Left ventricle; $E D$, end-diastole; $E S$, endsystole. 
model simulation was able to reproduce experimentally observed stretching of BZ fibers during isovolumic systole. ${ }^{40}$ Since in the present study we also had measurements of strain in the remote region, we allowed the value of $T_{\max }$ in the remote region to be optimized as well to best fit these strain measurements. It is somewhat surprising that $T_{\max }$ in the remote region decreases significantly owing to the Dor procedure.

\section{Stress Reduction}

A reduction in systolic BZ stress may stop or reduce nonischemic infarct extension-a process in which normally perfused segments adjacent to the infarct increase in size over time in response to high systolic stress. ${ }^{8,41}$ Our FEbased calculations show that end-diastolic and end-systolic fiber stress is decreased in the BZ after the Dor procedure.

However, the amount of stress reduction necessary to halt or reverse nonischemic infarct extension in the infarct BZ is unknown. In a recent study, Moustakidis and coworkers ${ }^{42}$ reported that peak systolic stress (circumferential) in normal sheep was approximately $12 \mathrm{kPa}$ (see Figure E3). It should be noted that the Dor procedure, which reduces end-systolic fiber stress to $31.1,17.6$, and $21.2 \mathrm{kPa}$ in the remote, intermediate BZ, and BZ near to the MI, does not succeed in "normalizing" stress. Further evaluation of end-systolic and end-diastolic stress levels in normal sheep using the methods employed in this study may be warranted.

\section{Limitations}

The primary limitation of the present study is the limited spatial resolution associated with our MRI acquisition. In several of our experiments, we acquired tagged short-axis images that were separated by $1 \mathrm{~cm}$. Since the long-axis lengths of repaired LVs were significantly less than those of the other LVs, strain comparisons could be made only in the short-axis slices 1 to $4 \mathrm{~cm}$ below the valves. Moreover, the $\mathrm{BZ}$ in the anterior LV wall was contained within the latter slice, but the other $\mathrm{BZ}$ regions were located below it. Thus, it is not entirely accurate to label all LV regions in the short-axis slice $4 \mathrm{~cm}$ below the valves as $\mathrm{BZ}$ regions.

\section{Conclusions and Future Directions}

The Dor procedure decreases end-diastolic and end-systolic stress but fails to improve contractility in the infarct BZ. Future work should focus on measures that will enhance BZ function alone or in combination with surgical remodeling.

\section{References}

1. Dor V, Saab M, Coste P, Kornaszewska M, Montiglio F. Left ventricular aneurysm: a new surgical approach. Thorac Cardiovasc Surg. 1989;37:11-9.

2. Aguiar Ribeiro GC, Antoniali F, Lopes MM, Costa CE, Albuquerque AN, Franchini KG. Left ventricular reconstruction brings benefit for patients with ischemic cardiomyopathy. J Card Fail. 2006;12:189-94.
3. Dor V, Di Donato M, Sabatier M, Montiglio F, Civaia F. Left ventricular reconstruction by endoventricular circular patch plasty repair: a 17-year experience. Semin Thorac Cardiovasc Surg. 2001;13:435-47.

4. Jones RH, Velazquez EJ, Michler RE, Sopko G, Oh JK, O'Connor CM, et al. the STICH Hypothesis 2 Investigators. Coronary bypass surgery with or without surgical ventricular reconstruction. $N$ Engl J Med. 2009;360:1705-17.

5. Homans DC, Asinger R, Elsperger KJ, Erlien D, Sublett E, Mikell F, et al. Regional function and perfusion at the lateral border of ischemic myocardium. Circulation. 1985;71:1038-47.

6. Guccione JM, Moonly SM, Moustakidis P, Costa KD, Moulton MJ, Ratcliffe MB, et al. Mechanism underlying mechanical dysfunction in the border zone of left ventricular aneurysm: a finite element model study. Ann Thorac Surg. 2001;71:654-62.

7. Walker JC, Ratcliffe MB, Zhang P, Wallace AW, Fata B, Hsu EW, et al. MRIbased finite-element analysis of left ventricular aneurysm. Am J Physiol Heart Circ Physiol. 2005;289):H692-700.

8. Jackson BM, Gorman JH, Moainie SL, Guy TS, Narula N, Narula J, et al. Extension of borderzone myocardium in postinfarction dilated cardiomyopathy. $J$ Am Coll Cardiol. 2002;40:1160-7; discussion 1168-1171.

9. Zhang P, Guccione JM, Nicholas SI, Walker JC, Crawford PC, Shamal A, et al. Left ventricular volume and function after endoventricular patch plasty for dyskinetic anteroapical left ventricular aneurysm in sheep. J Thorac Cardiovasc Surg. 2005; 130:1032-8.

10. Zhang P, Guccione JM, Nicholas SI, Walker JC, Crawford PC, Shamal A, et al. Endoventricular patch plasty for dyskinetic anteroapical left ventricular aneurysm increases systolic circumferential shortening in sheep. J Thorac Cardiovasc Surg. 2007; 134:1017-24.

11. Omens JH, May KD, McCulloch AD. Transmural distribution of three-dimensional strain in the isolated arrested canine left ventricle. Am J Physiol. 1991; 261(3 Pt 2):H918-28.

12. Moonly S. Experimental and computational analysis of left ventricular aneurysm mechanics [dissertation]. San Francisco (CA): Department of Bioengineering, University of California, San Francisco, with University of California, Berkeley; 2003.

13. Guccione JM, McCulloch AD, Waldman LK. Passive material properties of intact ventricular myocardium determined from a cylindrical model. J Biomech Eng. 1991;113:42-55.

14. Guccione JM, Waldman LK, McCulloch AD. Mechanics of active contraction in cardiac muscle: part II-cylindrical models of the systolic left ventricle. J Biomech Eng. 1993;115:82-90.

15. Dang AB, Guccione JM, Mishell JM, Zhang P, Wallace AW, Gorman RC, et al. Akinetic myocardial infarcts must contain contracting myocytes: finite-element model study. Am J Physiol Heart Circ Physiol. 2005;288:H1844-50.

16. Guccione JM, Costa KD, McCulloch AD. Finite element stress analysis of left ventricular mechanics in the beating dog heart. J Biomech. 1995;28:1167-77.

17. Lin DH, Yin FC. A multiaxial constitutive law for mammalian left ventricular myocardium in steady-state barium contracture or tetanus. $J$ Biomech Eng. 1998;120:504-17.

18. Usyk TP, Mazhari R, McCulloch AD. Effect of laminar orthotropic myofiber architecture on regional stress and strain in the canine left ventricle. $J$ Elasticity. 2000;61:143-64.

19. Stander N, Roux W, Eggleston T, Craig K. LS-OPT user's manual version 3.2. Livermore (CA): Livermore Software Technology Corporation; 2007.

20. Declerck J, Denney TS, Ozturk C, O'Dell W, McVeigh ER. Left ventricular motion reconstruction from planar tagged MR images: a comparison. Phys Med Biol. 2000;45:1611-32.

21. Denney TS Jr, Gerber BL, Yan L. Unsupervised reconstruction of a three-dimensional left ventricular strain from parallel tagged cardiac images. Magn Reson Med. 2003;49:743-54.

22. Krueger C, Tian L. A comparison of the general linear mixed model and repeated measures ANOVA using a dataset with multiple missing data points. Biol Res Nurs. 2004;6:151-7.

23. Wooding W. Planning pharmaceutical clinical trials: Basic statistical principals. Probability and mathematical statistics. New York: John Wiley; 1994. pp 34-6.

24. Artrip JH, Oz MC, Burkhoff D. Left ventricular volume reduction surgery for heart failure: a physiologic perspective. J Thorac Cardiovasc Surg. 2001;122: 775-82.

25. Dang AB, Guccione JM, Zhang P, Wallace AW, Gorman RC, Gorman JH 3rd, et al. Effect of ventricular size and patch stiffness in surgical anterior ventricular restoration: a finite element model study. Ann Thorac Surg. 2005;79:185-93. 
26. Moulton MJ, Creswell LL, Actis RL, Myers KW, Vannier MW, Szabó BA, et al. An inverse approach to determining myocardial material properties. J Biomech. 1995;28:935-48.

27. Myers RH, Montgomery DC. Response surface methodology. New York: John Wiley; 1995.

28. Stander N, Craig KJ. On the robustness of a simple domain reduction scheme for simulation based optimization. Eng Computations. 2002;19:431-50.

29. Guccione JM, McCulloch AD. Mechanics of active contraction in cardiac muscle: part I-constitutive relations for fiber stress that describe deactivation. J Biomech Eng. 1993;115:72-81.

30. Kentish JC, ter Keurs HE, Ricciardi L, Bucx JJ, Noble MI. Comparison between the sarcomere length-force relations of intact and skinned trabeculae from rat right ventricle. Influence of calcium concentrations on these relations. Circ Res. 1986; 58:755-68.

31. Dispersyn G, Mesotten L, Meuris B, Maes A, Mortelmans L, Flameng W, et al. Dissociation of cardiomyocyte apoptosis and dedifferentiation in infarct border zones. Eur Heart J. 2002;23:849-57.

32. Narula N, Narula J, Zhang P, Haider N, Raghunath P, Britten R, et al. Is the myofibrillarlytic myocyte a forme fruste apoptotic myocyte? Ann Thorac Surg. 2005; 79:1333-7.

33. Wilson EM, Moainie SL, Baskin JM, Lowry AS, Deschamps AM, Mukherjee R, et al. Region- and type-specific induction of matrix metalloproteinases in postmyocardial infarction remodeling. Circulation. 2003;107:2857-63.

34. Mukherjee R, Mingoia JT, Bruce JA, Austin JS, Stroud RE, Escobar GP, et al. Selective spatiotemporal induction of matrix metalloproteinase- 2 and matrix metalloproteinase-9 transcription after myocardial infarction. Am J Physiol Heart Circ Physiol. 2006;291:H2216-28.

35. Sawicki G, Leon H, Sawicka J, Sariahmetoglu M, Schulze CJ, Scott PG, et al. Degradation of myosin light chain in isolated rat hearts subjected to ischemia- reperfusion injury: a new intracellular target for matrix metalloproteinase-2. Circulation. 2005;112:544-52.

36. Gao CQ, Sawicki G, Suarez-Pinzon WL, Csont T, Wozniak M, Ferdinandy P et al. Matrix metalloproteinase-2 mediates cytokine-induced myocardial contractile dysfunction. Cardiovasc Res. 2003;57:426-33.

37. Biagini E, Galema TW, Schinkel AF, Vletter WB, Roelandt JR, Ten Cate FJ Myocardial wall thickness predicts recovery of contractile function after primary coronary intervention for acute myocardial infarction. J Am Coll Cardiol. 2004, 43:1489-93.

38. Cwajg JM, Cwajg E, Nagueh SF, He ZX, Qureshi U, Olmos LI, et al. End-diastolic wall thickness as a predictor of recovery of function in myocardial hibernation: relation to rest-redistribution T1-201 tomography and dobutamine stress echocardiography. J Am Coll Cardiol. 2000;35:1152-61.

39. Nagueh SF, Mikati I, Weilbaecher D, Reardon MJ, Al-Zaghrini GJ, Cacela D et al. Relation of the contractile reserve of hibernating myocardium to myocardial structure in humans. Circulation. 1999;100:490-6.

40. Moulton MJ, Downing SW, Creswell LL, Fishman DS, Amsterdam DM, Szabó BA, et al. Mechanical dysfunction in the border zone of an ovine model of left ventricular aneurysm. Ann Thorac Surg. 1995;60:986-97; discussion 998.

41. Jackson BM, Gorman JH 3rd, Salgo IS, Moainie SL, Plappert T, St JohnSutton M, et al. Border zone geometry increases wall stress after myocardial infarction: contrast echocardiographic assessment. Am J Physiol Heart Circ Physiol. 2003;284:H475-9

42. Moustakidis P, Maniar HS, Cupps BP, Absi T, Zheng J, Guccione JM, et al. Altered left ventricular geometry changes the border zone temporal distribution of stress in an experimental model of left ventricular aneurysm: a finite element model study. Circulation. 2002;106(12 Suppl. 1):I168-75.

43. Tozeren A. Continuum rheology of muscle contraction and its application to cardiac contractility. Biophys $J$. 1985;47:303-9. 


\section{Appendix}

\section{Diastolic Constituitive Relationship (Material Property Law).}

The passive myocardium was described by a strain energy function, $W$, that is transversely isotropic with respect to the local fiber direction,

$$
W=\frac{C}{2}\left(\exp ^{b_{\mathrm{f}} E_{11}^{2}+b_{\mathrm{t}}\left(E_{22}^{2}+E_{33}^{2}+E_{23}^{2}+E_{32}^{2}\right)+b_{\mathrm{fs}}\left(E_{12}^{2}+E_{21}^{2}+E_{13}^{2}+E_{31}^{2}\right)-1}\right)
$$

where $C, b_{\mathrm{f}}, b_{\mathrm{t}}$, and $b_{\mathrm{fs}}$ are diastolic myocardial material parameters. $E_{11}$ is strain in fiber direction, $E_{22}$ is cross-fiber inplane strain, $E_{33}$ is radial strain transverse to the fiber direction, and the rest are shear strains.

\section{Systolic Constituitive Relationship}

Systolic contraction was modeled as the sum of the passive stress derived from the strain energy function and an active fiber directional component, $\mathbf{T}_{\mathbf{0}}$, which is a function of time, $t$, peak intracellular calcium concentration, $\mathrm{Ca}_{0}$, sacromere length, $l$, and maximum isometric tension achieved at the longest sacromere length, $T_{\max }{ }^{14}$,

$S=p J C^{-1}+2 J^{-2 / 3} \operatorname{Dev}\left(\frac{\partial \tilde{W}}{\partial C}\right)+\mathbf{T}_{\mathbf{0}}\left\{t, C a_{0}, l, T_{\max }\right\}$

where $S$ is the second Piola-Kirchoff stress tensor, $p$ is the hydrostatic pressure introduced as the Lagrange multiplier needed to ensure incompressibility and was calculated from the bulk modulus of water, $J$ is the Jacobian of the deformation gradient tensor, $C$ is the right Cauchy-Green deformation tensor, Dev is the deviatoric projection operator, and $\tilde{W}$ is the deviatoric contribution of the strain energy function, $W$ (equation 3).

The modified Hill equation is used to describe the sigmoidal relation between active tension and calcium concentration in skinned cardiac muscle.

$$
T_{\mathrm{o}}=T_{\text {max }, \text { twitch }} \frac{c a_{o}^{n}}{c a_{o}^{n}+E c a_{50}^{n}}
$$

To describe the effect of twitch duration, Tozeren ${ }^{43}$ suggested scaling the modified Hill equation with an internal variable, $C_{t}$ as follows:

$T_{0}=T_{\text {max }, \text { twitch }} \frac{C a_{0}^{2}}{C a_{0}^{2}+E C a_{50}^{2}} C_{t}$

where

$C_{t}=\frac{1}{2}\left(1-\cos \left(\frac{0.25}{m l_{R} \sqrt{2 E_{11}+1}+b}+1\right) \pi\right)$

and $m$ and $b$ are constants. $n$ is assumed to be 2 . Note also that:

$T_{\text {max }, \text { skinned-fiber }}=T_{\text {max }, \text { twitch }} C_{t}$

The length-dependent calcium sensitivity, $E C a_{50}$, was determined by Guccione, McCulloch, and Waldman ${ }^{14}$ to be:

$E C a_{50}=\frac{\left(C a_{0}\right)_{\max }}{\sqrt{\exp \left[B\left(l_{R} \sqrt{2 E_{11}+1}-l_{0}\right)\right]-1}}$

where $B$ is a constant, $\left(C a_{0}\right)_{\max }$ is the maximum peak intracellular calcium concentration, $l_{0}$ is the sarcomere length at which no active tension develops, and $l_{\mathrm{R}}$ is the stress-free sarcomere length. 

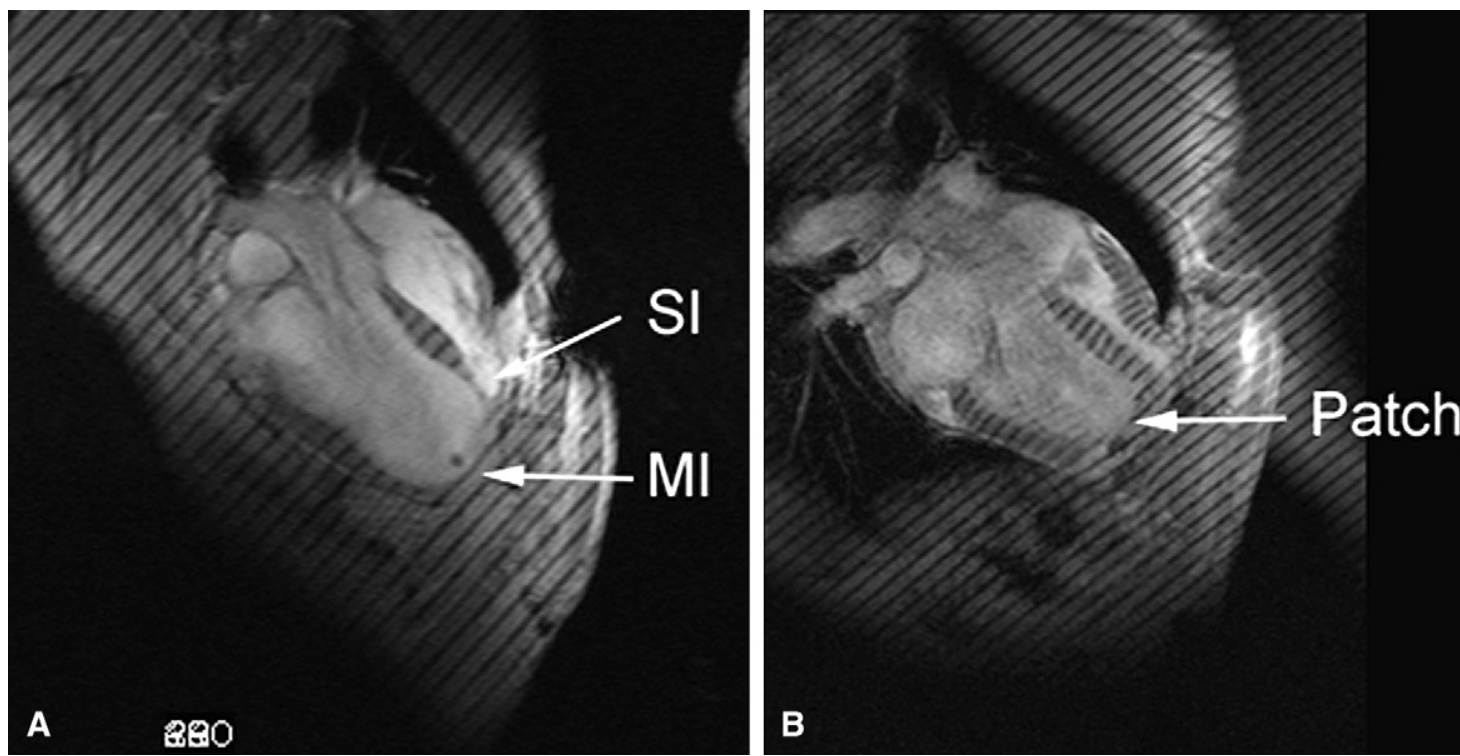

FIGURE E1. Long -axis magnetic resonance images after myocardial infarction (A) and 2 weeks after the Dor procedure (B) in sheep. MI, Dykinetic infarct; SI, septal infarct. All images were obtained at end-systole.

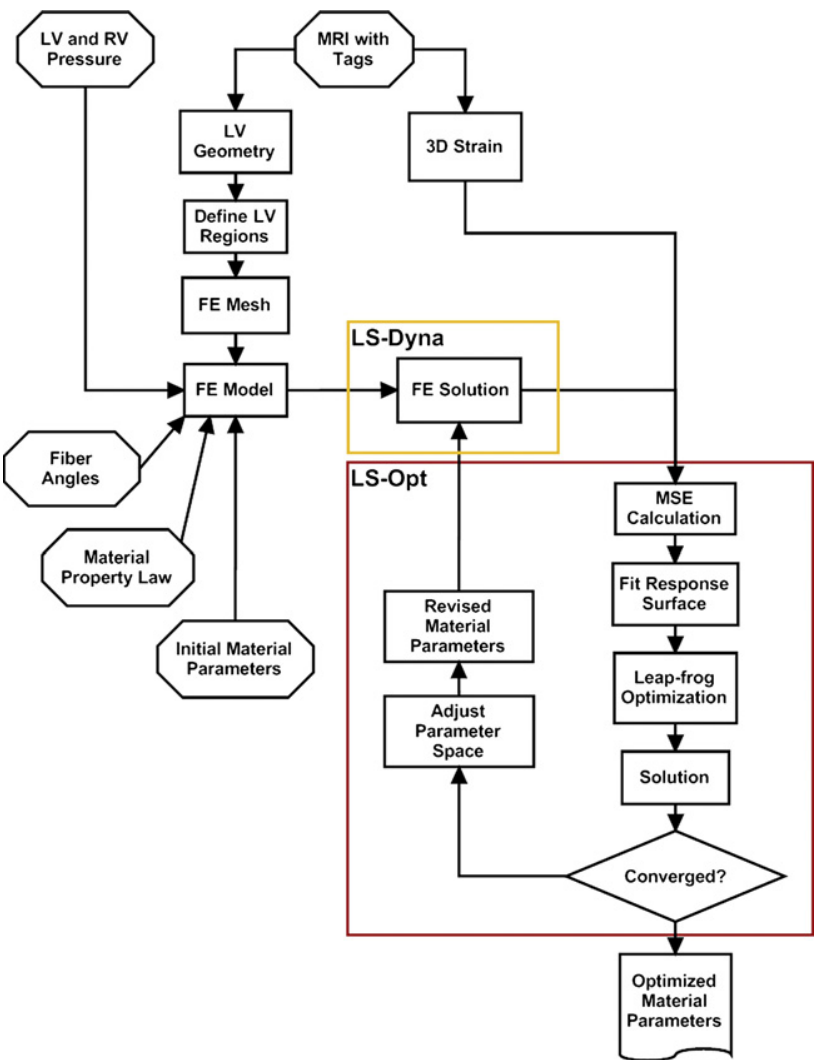

FIGURE E2. Flow chart of finite element/material property optimization method. MRI, Magnetic resonance image; LV, left ventricular; RV, right ventricular; $3 D$, 3-dimensional; $F E$, finite element; $M S E$, mean square error. 


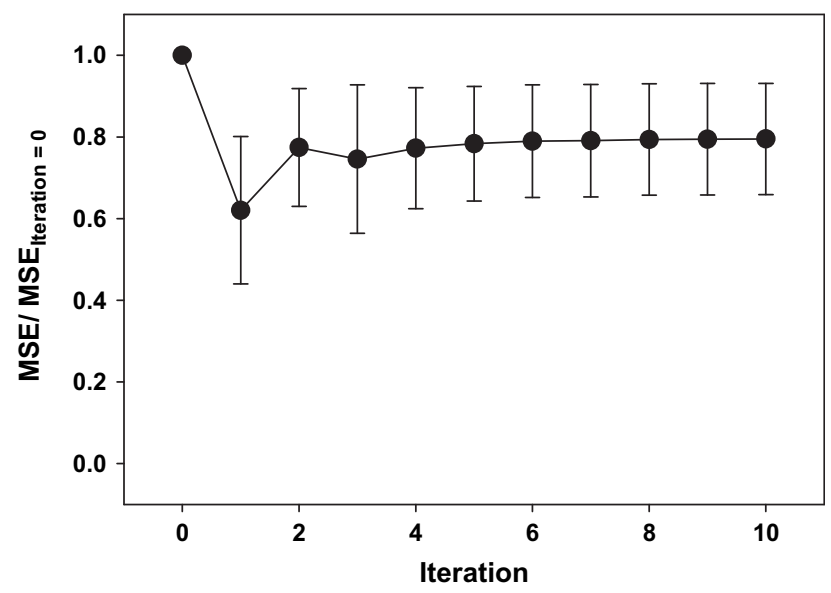

FIGURE E3. Convergence of mean square error (MSE) during the optimization. MSE values are normalized to the starting MSE value for comparison.
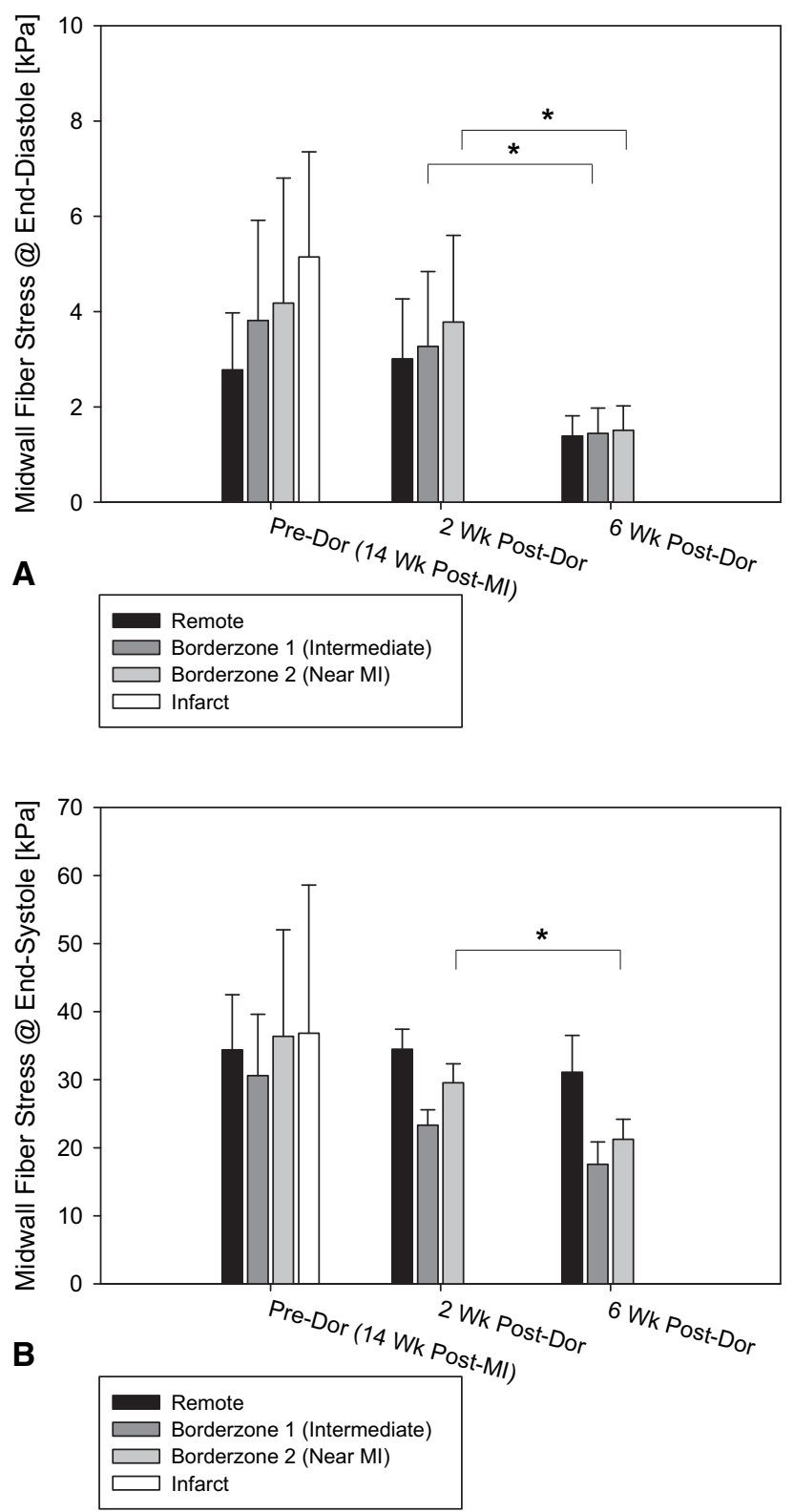

FIGURE E4. Effect of Dor procedure on fiber stress at end-diastole (A) and end-systole (B). Note the decrease in fiber stress in the infarct border zone. There was an overall effect of time and region but the change in border zone 2 was not significant. Data are presented as mean + standard deviation. $* P<.05 . M I$, Myocardial infarction. 
TABLE E1. Effect of Dor procedure on left ventricular pressure and volume

\begin{tabular}{lccc}
\hline & Before Dor & $\begin{array}{c}\text { Two weeks } \\
\text { after Dor }\end{array}$ & $\begin{array}{c}\text { Six weeks } \\
\text { after Dor }\end{array}$ \\
\hline LVP at ED $(\mathrm{mm} \mathrm{Hg})$ & $8.9 \pm 5.5$ & $17.5 \pm 5.6^{*}$ & $10.5 \pm 3.9$ \\
LVP at ES $(\mathrm{mm} \mathrm{Hg})$ & $96.2 \pm 23.2$ & $105.7 \pm 20.0$ & $123.2 \pm 19.4$ \\
EDV $(\mathrm{mL})$ & $161.6 \pm 37.1$ & $104.1 \pm 29.2^{*}$ & $101.3 \pm 22.2^{*}$ \\
ESV $(\mathrm{mL})$ & $130.1 \pm 36.0$ & $68.0 \pm 29.5^{*}$ & $66.3 \pm 14.3^{*}$ \\
SV $(\mathrm{mL})$ & $31.5 \pm 9.4$ & $31.9 \pm 13.9$ & $35.0 \pm 10.8$ \\
EF $(\%)$ & $20.6 \pm 8.1$ & $33.0 \pm 11.0$ & $34.4 \pm 7.1^{*}$ \\
\hline
\end{tabular}

Values are mean \pm standard deviation. $L V P$, Left ventricular pressure; $E D V$, enddiastolic volume; $E S V$, end-systolic volume; $\mathrm{SV}$, stoke volume; $E F$, ejection fraction. $* P<.052$ - and 6-week Dor versus pre-Dor.

TABLE E2. Comparison between experimentally measured and finite element predicted volume and circumferential strain

\begin{tabular}{lcc}
\hline & Experiment & Simulation \\
\hline LV volume @ ED $(\mathrm{mL})$ & $94.3 \pm 25.1$ & $94.2 \pm 25.1$ \\
LV volume @ ES $(\mathrm{mL})$ & $73.6 \pm 26.0$ & $75.6 \pm 27.5$ \\
Circumferential strain & & \\
@ Base & $-0.091 \pm 0.041$ & $-0.067 \pm 0.029$ \\
@ Remote & $-0.114 \pm 0.037$ & $-0.108 \pm 0.046$ \\
@ BZ & $-0.030 \pm 0.015$ & $-0.033 \pm 0.026$ \\
\hline Values are mean \pm standard deviation. $L V$, Left ventricle; $E D$, end-diastole; $E S$, end- \\
systole; $B Z$, border zone.
\end{tabular}

